\title{
Kontribusi Pemikiran Islam Sayyid Ahmad Khan di Dunia Islam India
}

\author{
Muh. Ilham Usman \\ Sekolah Tinggi Agama Islam Negeri Majene \\ Ilhamusman1983stainmajene.ac.id \\ Baharil \\ Mahasisiwa Prodi Ilmu al-Qur'an dan Tafsir \\ Sekolah Tinggi Agama Islam Negeri Majene
}

\begin{abstract}
This article discusses the thoughts and ideas of Sir Sayyid Ahmad Khan during the colonial era of India by the British Empire until the formation of the state of Pakistan. The purpose of this paper is to complement the previous studies on Sir Sayyid Ahmad Khan's thoughts which have been widely studied. This research is a library research. Sources of data are obtained from primary books written by Sir Sayyid Ahmad Khan and also secondary books that examine the thoughts of Sir Sayyid Ahmad Khan written by other people. The results of the research showed that Sir Sayyid Ahmad Khan hated the colonialism carried out by the British empire, but the path taken against it was not confrontation, but diplomacy. In addition, Indian Muslims should not only surrender to their destiny, but must be active and creative in living their lives as understood by Qadariyah in classical Islamic theology. By adopting Qadariyah ideology, Indian Muslims will utilize all the potential given by Allah $S W T$ in living this life and existence.
\end{abstract}

\section{Keyword: England, Takdir, Qadariyah, dan Diplomacy}

\section{Abstrak}

Artikel ini membahas tentang pemikiran dan gagasan Sir Sayyid Ahmad Khan di masa penjajahan India oleh kerajaan Inggris hingga terbentuknya negara Pakistan. Tujuan penulisan ini untuk melengkapi penelitian-penelitian terdahulu tentang pemikiran Sir Sayyid Ahmad Khan yang telah banyak dikaji. Penelitian ini merupakan penelitian kepustakaan. Sumber data diperoleh dari buku-buku primer yang ditulis oleh Sir Sayyid Ahmad Khan dan juga buka-buku sekunder yang mengkaji pemikiran Sir Sayyid Ahmad Khan yang ditulis orang lain. Adapun hasil penelitian didapatkan bahwa Sir Sayyid Ahmad Khan membenci penjajahan yang dilakukan oleh kerajaan Inggris, akan tetapi untuk jalan yang ditempuh untuk melawannya bukanlah konfrontasi, melainkan diplomasi. Selain itu, umat Islam India jangan hanya pasrah terhadap takdir, melainkan harus aktif dan kreatif dalam menjalankan hidup sebagaimana paham Qadariyah dalam teologi klasik Islam. Dengan mengadopsi paham Qadariyah, umat Islam India akan mendayagunakan seluruh potensi yang diberikan oleh Allah $S_{w t}$ dalam menjalani hidup dan kehidupan ini.

Kata Kunci: Inggris, Takdir, Qadariyah, dan Diplomasi 


\section{A. Pendahuluan}

Ahmad Khan adalah putra Sayyid Muhammad Muttaqi Khan, ia lahir di Delhi pada tanggal 17 Oktober 1817. Nenek moyangnya berasal dari semenanjung Arabia dan kemudian hijrah ke Herat dan dari sana ia ke India selama pemerintahan rezim Akbar Shah. ${ }^{1}$ Nama lengkapnya Sir Sayyid Ahmad Khan Ibnu al-Muttaqi Ibnu al-Hadi al-Hasani as-Dahlawi.

Ayahnya al-Muttaqi adalah seorang yang saleh. Ia mempunyai pengaruh besar di kerajaan Mughal pada masa pemerintahan Akbar Syah II (1806-1837 M). Sedangkan kakeknya Sayyid Hadi pernah menjabat komandan militer pada masa pemerintahan Alaghir II (1754-1759). Dan kakek dari pihak ibu, Khawaja Fariduddin pernah menjadi perdana menteri pada raja Mughal Akbar Syah II selama kurang lebih 8 tahun. ${ }^{2}$ Ahmad Khan dari pihak bapaknya masih mempunyai pertalian darah dengan Nabi Muhammad Saw melalui Husen R.a dari keturunan Fatimah az-Zahra dan Ali bin Abi Thalib. Oleh karena itulah, ia bergelar sayyid dan ibunya adalah seorang wanita cerdas dan pandai mendidik anak-anaknya. ${ }^{3}$

Mir Muttaqi ayah Sayyid Ahmad Khan mengundurkan diri menjadi pejabat di istana, yang kemudian seluruh hidupnya dihabiskan di jalan "pensucian spiritual" tarekat Naqsyabandiyah. Sebagai pengikut tarekat, ayah Sayyid Ahmad Khan mendidik putranya dengan pendidikan pengetahuan agama secara tradisional dan "menyerahkannya” ke Syekh Ghulam Ali yang kala itu sebagai mursyid tarekat Naqsyabandiyah. ${ }^{4}$ Di samping itu, selain memelajari Alqur'an dan ulum Alqur'an, ia juga mempelajari bahasa Persia dan Arab, matematika, mekanika, h. 199.

${ }^{1}$ Martijn Theodoor Houtsma, The First Encyclopedia of Islam (Leiden: E. J. Brill, 1987),,

2 Zainur Arifin, 'Politik Pendidikan Islam Masa Modern: Membaca Gagasan Tokoh Pembaharu Di Negara Turki, India Dan Mesir', Tafaqquh: Jurnal Penelitian Dan Kajian Keislaman, 3.1 (2015)., h. 90. h. 85 .

${ }^{3}$ Dewan Redaksi Ensiklopedi Islam, 'Ensiklopedi Islam’ (Ichtiar Baru Van Hoeve, 1993)., h. 160 .

\footnotetext{
${ }^{4}$ Gunawan B. Dulumina, 'Gerakan Pembaruan Sayyid Ahmad Khan', Hunafa, 2.2 (2005).,
} 
geometri, ilmu kedokteran dan juga sejarah, serta banyak menghabiskan waktu senggang dengan membaca buku ilmu pengetahuan dalam berbagai bidang ilmu. ${ }^{5}$ Dengan kebiasaan membaca dan memelajari pengetahuan lainnya, membuat Sayyid Ahmad Khan dikenal dengan pemuda yang berwawasan luas dan berpikiran maju serta dapat menerima segala ilmu pengetahuan modern. Bahkan, para cendekiawan muslim internasional memasukkan Sayyid Ahmad Khan sebagai tokoh pembaharuan Islam abad ke-19 yang mempunyai gagasan brilian. ${ }^{6}$

Ketika menginjak usia 19 tahun, tepat pada tahun 1838 M, sang ayah meninggalkannya menuju peristirahatan terakhir. Disebabkan ibunya enggan menerima pensiunan dari Istana, maka untuk menyambung keberlangsungan kehidupan keluarganya, Sayyid Ahmad Khan mulai "membanting-tulang" dengan bekerja di EIC (The East India Company) agar dapurnya tetap mengepul.

Untuk mendapatkan penghasilan tambahan, Sayyid Ahmad Khan juga bekerja sebagai juru tulis/ketik di departemen pemasyarakatan (Criminal Departement) di Delhi. Pekerjaaan yang terakhir, mendapat kritikan dari keluarganya yang sangat anti-Inggris. Bekerja dan belajar terus digelutinya sepanjang jalan masa mudanya, hal ini bisa disaksikan pada umur 24 tahun, tepatnya pada tahun $1841 \mathrm{M}$, ia diangkat sebagai Munshif (pembantu Hakim) di Patihpur Distrik Agra.

Pada tahun 1846 M, Sayyid Ahmad Khan yang berumur 29 tahun kembali ke Delhi untuk meneruskan studinya. Tiada kata lelah untuk menambah pengetahuan. Tidak ada kata letih dalam hidupnya untuk terus menuntut pengetahuan, hingga beberapa tahun sesudah itu, ia pun diangkat lagi sebagai Munshif di Bignaur dan di sanalah, ia berada ketika terjadi peristiwa $1857 .{ }^{7}$

${ }^{5}$ Dewan Redaksi Ensiklopedi Islam., h. 86.

${ }^{6}$ Kemal A. Faruki, 'Pakistan: "Islamic Government and Society", in Islam Ind Asia, Religion, Politics, and Society (Oxford: Oxford University Press (OUP), 1987), h. 54. h. 24-25.

${ }^{7}$ H.A.R. dan J.H. Krames Gibb, Shorter Encyclopedia of Islam (Leiden: E. J. Brill, 1961)., 
Peristiwa "pemberontakan” sisa-sisa kekuatan kerajaan Mughal terhadap tentara Inggris, yang membuat Inggris marah besar, hingga "membabat-habis" para pejuang Mughal.

Menyaksikan peristiwa ini, Sayyid Ahmad Khan melakukan kritik terhadap para pejuang yang anti-Inggris yang selalu melancarkan penyerangan. Beliau menyarankan agar konfrontasi diakhiri diganti dengan kompromi antara pejuang anti-Inggris dan Inggris, yang hanya menimbulkan banyaknya jiwa yang melayang, di satu sisi, hanya akan melahirkan dendam kesumat. Ada baiknya melakukan kompromi saja, mencari jalan tengah sebagai solusi dari perseteruan ini. Ia pun mulai melakukan kompromi dengan duduk perkaranya bahwa pejuang anti-Inggris, bukanlah Muslim yang menjadi aktor utamanya, para pejuang muslim "marah" kepada Inggris karena dianggap melakukan Kristenisasi di India. Di samping itu, para tentara Inggris sering melakukan tindakan dan perbuatan yang memicu penyerangan dan konfrontasi. ${ }^{8}$

Sayyid Ahmad Khan yang melakukan kompromi atas dua kubu yang saling menyerang, sehinga karena jasanya terhadap Inggris dalam peristiwa $1857 \mathrm{M}$, maka diberikan penghargaan dari penguasa kerajaan Inggris. Penghargaan tersebut berupa gelar kehormatan kebangsawanan Inggris, yaitu Sir serta diajak ke Inggris untuk diperkenalkan segala kemajuan Inggris utamanya di bidang ilmu dan teknologi. ${ }^{9}$

Sayyid Ahmad Khan yang terpesona dengan kemajuan pendidikan dan sains di Barat, pada tahun 1863 membuatnya mendirikan Majelis Sains di Aligarh yang bertujuan untuk memotivasi generasi muda Islam untuk menyukai dan cinta terhadap ilmu pengetahuan Barat. ${ }^{10}$ Selang tiga tahun kemudian, tepatnya pada

\footnotetext{
${ }^{8}$ Saidul Amin, 'Pembaharuan Pemikiran Islam Di India', Jurnal Ushuluddin, XVIII.1 (2012)., h. 88 .

9 Harun Nasution, Pembaharuan Dalam Islam; Sejarah Pemikiran Dan Gerakan, IX (Jakarta: Bulan Bintang, 1992)., h. 165.

${ }^{10}$ Ahmad Nabil Bin Amir, 'Sir Sayyid Ahmad Khan Dan Gerakan Pembaharuan Aligarh Di India', El-Buhuth, 2.2 (2020)., h. 123.
} 
tahun 1866, Sayyid Ahmad Khan membuka biro penerbitan yang diberi nama Aligarh Institute. Atas capaian yang dicapai, pihak kerajaan Inggris pada tahu 1869 memberikan sebuah "hadiah" yakni berkunjung ke Inggris untuk memelajari sistem, metode dan cara pendidikan Barat, di Oxford University dan Cambridge Universty. Sekembalinya, dari Inggris tahun 1870, ia pun berusaha menyebarkan informasi tentang kemajuan yang telah dicapai Inggris di bidang ilmu dan teknologi.

Cita-cita luhur untuk meningkatkan kualitas umat muslim India, tercetuslah ide pada Mei 1875 Sir Sayyid Ahmad Khan mendirikan sekolah modern yang diberi nama "Muhammadan Anglo-Oriental College" (MAOC) atau dikenal dengan nama "Madrasah Al-Ulum Musalmanan di Aligarh dan Lord Lytton (raja muda Inggris) menjadi orang yang pertama kali meletakkan dalam pembangunan gedung ini dilaksanakan pada bulan Januari $1877 .{ }^{11}$ Pendirian sekolah ini mempunyai visi dan misi untuk mengangkat pendidikan dasar pendidikan modern yang mengkhususkan kepada rekonstruksi dan pembaharuan. Pendirian lembaga pendidikan ini merupakan upaya memadukan sistem pendidikan modern dengan nilai-nilai Islam. Model kurikulumnya sebagian mengacu pada Oxford University dan Cambridge University.

"Muhammadan Anglo-Oriental College" (MAOC) inilah kurang-lebih 43 tahun kemudian, pada tahun 1920 berubah statusnya menjadi Aligarh Muslim University (AMU). ${ }^{12}$ Maka tak heranlah, jika Sir Sayyid Ahmad Khan, selain dikenal sebagai pembaharu pemikiran Islam, juga dikenal di seantero dunia sebagai pelopor pendidikan Islam di India yang cita-citanya untuk memajukan umat Islam India. $^{13}$

\footnotetext{
${ }^{11}$ Arifin., h. 96.

12 Amir., h. 124.

${ }^{13}$ Nasution, Pembaharuan Dalam Islam; Sejarah Pemikiran Dan Gerakan., h. 170.
} 
Lembaga pendidikan MAOC $^{14}$ yang telah didirikan ini dibentuk sesuai dengan model sekolah di Inggris dengan memakai bahasa pengantar adalah bahasa Inggris, kepala sekolah berkebangsaan Inggris, guru serta para stafnya juga kebanyakan orang Inggris. Sebagian besar dari mata pelajarannya adalah ilmu pengetahuan modern. Akan tetapi, pendidikan agama juga tidak diabaikan, bahkan ketaatan siswa menjalankan ajaran agama diperhatikan dan dipentingkan. Sekolah ini terus mengalami perkembangan dan pada tahun 1920 menjadi perguruan tinggi yang dikenal dengan Universitas Islam Aligarh. Tujuan Universitas ini adalah memadukan antara pendidikan agama dengan kajian-kajian sains modern. Oleh karena itu, dalam pengembangan lembaga pendidikan di India-Pakistan nama Sayyid Ahmad Khan patutlah dicatat dengan tintas emas peradaban. ${ }^{15}$

Usaha besar Sayyid Ahmad Khan dapatlah diibaratkan sebagai penerang di ujung lorong kegelapan umat Islam India. mempunyai besar pengaruhnya terhadap pembaharuan Islam di India adalah melalui jalur pendidikan. Hal ini bisa disaksikan, tindakan Sayyid Ahmad Khan dalam membangun lembaga pendidikan yang bergengsi di daratan India-Pakistan, sejak tahun 1859 hingga akhir hayatnya.

Di samping itu, Sayyid Ahmad Khan selain menuangkan gagasannya lewat tindakan dan perbuatan, ia juga menuangkannya dalam pikiran karya tulis yang secara garis besar, meliputi tiga bidang, yakni sejarah, agama dan pendidikan, sebagai berikut:

a. Asrar al-Sanadid (1847) tentang arkeologi di India;

b. Jam i-Jam (1940) berbicara tentang sejarah raja-raja Mughal serta komentar kritis terhadap keruntuhannya;

c. Silsilat ul-Muluk (1852);

${ }^{14}$ Mukti Ali, Alam Pikiran Islam Modern Di India Dan Di Pakistan, IV (Bandung: Mizan, 1998)., h. 66.

${ }^{15}$ Nasution, Pembaharuan Dalam Islam; Sejarah Pemikiran Dan Gerakan., h. 165. 
d. The Loyal Muhammadans of India (1860). Buku ini memuat nama-nama orang Islam terkemuka yang memihak kepada Inggris pada saat terjadinya pemberontakan Mutiny.

e. The Causes of Indian Revolt;

f. Tarikh I-Firuz Shahi;

g. Tuzuk i-Jahangiri;

h. Tafsir al-Qur'an (tujuh jilid) yang ditulisnya pada periode 1880-1904.

i. Risalah Ibtal al-Ghulami (1893) yang menyuarakan pandangan Islam tentang penghapusan sistem perbudakan.

j. Tabyin al-Kalam fi Tafsir al-Taurat wa al-Injil ala Mullat al-Islam yang mempersoalkan bagaimana Injil memandang Nabi Muhammad.

k. Tahzib al-Akhlaq, yang berisi kumpulan tulisan dalam majalah-majalah.

Akhirnya pada tanggal 27 Maret 1898, Sir Sayyid Ahmad Khan berpulang kerahmatullah. Setelah menderita sakit beberapa bulan lamanya. Ia meninggal dalam usia 81 tahun. Hidupnya telah dipasrahkan demi agama Islam dan kejayaan ummatnya, sesuai dengan ide dan caranya sendiri. Ia dimakamkan di Aligarth. Banyak rakyat India ikut mengantarkan jenazahnya ke peristirahatan yang terakhir yang terdiri dari pelbagai Agama, Bangsa dan Kasta.

Dari latar belakang kehidupan Sayyid Ahmad Khan dan lika-likunya dalam memperjuangkan kemerdekaan India dari penjajah Inggris, sehingga penulis membuat rumusan masalah dalam untuk menjawab kotribusi apa yang diberikan oleh Sayyid Ahmad Khan dalam memperjuangkan dan membangkitkan jiwa merdeka umat Islam India, yakni bagaimana sayyid Ahmad Khan membangkitkan jiwa pasrah umat Islam dari penjajahan? Bagaimana metode yang dilakukan oleh Sayyid Ahmad Khan dalam memperjuangkan umat Islam India? Serta bagaimana pula membangun mental umat Islam India yang pasrah akan ketertinsan oleh penjajah kolonial Inggris?. Inilah tiga rumusan masalah yang akan dieksplorasikan dalam artikel ini. 


\section{B. Sepercik Gagasan Sir Sayyid Ahmad Khan \\ a. Urgensi Paham Qadariyah}

Keyakinan Sayyid Ahmad Khan terhadap akal manusia yang punya kekuatan, maka dengan sendirinya ada kebebasan manusia dalam menentukan kehendak dan perbuatannya. Menurutnya, manusia dianugerahi oleh Allah Swt daya berpikir yang disebut akal dan daya pikir untuk mewujudkan kehendaknya. Hal ini sesuai dengan paham yang dianut paham qadariyah dan kaum Mu'tazilah di zaman klasik, yang dengan pahamnya, Islam di masa Abbasiyah mengalami kemajuan, terutama Bagdhad dan Bashrah. ${ }^{16}$

Harun Nasution memberikan defenisi bahwa paham Qadariyah adalah paham yang berpendapat bahwa manusia mempunyai kemerdekaan dan kebebasan dalam menentukan lika-liku dan perjalanan hidupnya. ${ }^{17}$ Dalam artian bahwa paham Qadariyah menjadikan manusia mandiri, bebas dan punya kekuatan dalam mewujudkan tindakan dan perbuatannya. Paham ini memberikan arti bahwa Qadariyah adalah manusia mempunyai qudrah atau kekuatan untuk merealisasikan perbuatan-perbuatannya, hal ini didasarkan dalam QS. Ar-Ra'd/13: 11 yang terjemahannya: "Sesungguhnya Allah Swt tidak merubah apa yang ada pada sesuatu bangsa, sehingga mereka merubah apa yang ada pada diri mereka". Dan juga pada QS. Al-Fussilat/41: 40 yang terjemahannya yakni: "Buatlah apa yang kamu kehendaki, sesungguhnya Ia melihat apa yang kamu perbuat”.

Sir Sayyid Ahmad Khan menyaksikan telah terjadi kemunduran umat Islam India yang disebabkan oleh "tidak mau mengakui" kekuatan akal dan kebebasan manusia untuk memeroleh ilmu pengetahuan dan menciptakan teknologi modern yang membuat negara Eropa, khususnya Inggris sebagai kerajaan nomor wahid kala itu, sehingga melakukan ekspansi ke tanah India dan melakukan eksploitasi terhadap sumber daya alamnya (SDA). Kemunduran umat Islam India juga

16 W.C. Smith, Modern Islam In India : A Social Analiysis (London: Oxford University Press, 1946),, h. 22.

${ }^{17}$ Harun Nasution, Teologi Islam: Aliran-Aliran Sejarah Analisa Perbandingan (Jakarta: UI Press, 1986)., h. 31. 
disebabkan lamanya penjajahan yang dilakukan oleh Inggris, sehingga rakyat India (Hindu dan Islam) mempunyai jiwa mental inlander dalam dirinya, sehingga tidak mampu lagi menyaingi dan melakukan perlawanan ke Inggris. Begitu juga umat Islam India yang dalam jiwanya menubuh "rasa rendah diri" terhadap penjajah, sehingga bangsa Inggris dianggap superior di mata umat Islam. Dan tragisnya, umat Islam India selalu kalah dalam perlawanannya melawan penjajah Inggris dan kekalahan itu dianggap sebagai takdir yang telah ditetapkan oleh sang Khalik.

Sayyid Ahmad Khan tampil untuk mengkontra paham menerima takdir apa adanya dengan cara menghidupkan kembali paham kebebasan manusia dalam berkehendak. Sayyid Ahmad Khan percaya bahwa manusia sendirilah yang menentukan nasibnya di masa depan, jika manusia hanya pasrah dan tidak berbuat apa-apa, maka Inggris akan terus menjajah. Oleh karena itu, Sayyid Ahmad Khan menggelorakan paham bahwa umat Islam mesti "bergerak" dalam memperjuangkan dan mengusir penjajah Inggris dari tanah tercintanya. Akan tetapi, dalam melakukan perjuangan perlu dilakukan dengan cara diplomasi dengan penjajah Inggris. Jika melakukan perjuangan dengan cara konfrontasi, maka yang terjadi, umat Islam India kemungkinannya akan kalah. Oleh karena itu, cara yang ditempuh adalah melakukan diplomasi dengan Inggris untuk menciptakan win-win solution.

Di satu sisi, Sayyid Ahmad Khan dalam mengcounter paham pasrah terhadap takdir, ia melakukan kritik terhadap pemahaman Barat yang memberi nilai lebih kepada kebebasan manusia sehingga meminimalisasi "campur-tangan dan keberadaan" sang Khalik. Tetapi di sisi lain, ia juga melakukan otokritik terhadap sebagian umat Islam India yang pasrah pada kehendak takdir. ${ }^{18}$ Sayyid Ahmad Khan berusaha menghidupkan kembali paham Mu'tazilah yang percaya tentang kebebasan akal pada manusia dan manusia bebas berkehendak, sehingga Sayyid Ahmad Khan dikatakan oleh A.H. Al-Biruni sebagi pemimpin Mu’tazilah

${ }^{18}$ Hasanul Rizqa, 'Pemikiran Sayyid Ahmad Khan Tentang Pendidikan', Republika.Co.Id (Jakarta, 8 April 2019). 
modern. ${ }^{19}$ Nampaknya Sayyid Ahmad Khan berpendapat bahwa jika paham ini tidak dikembangkan dalam teologi Islam, maka umat Islam dalam keadaan statis dan sulit untuk maju. ${ }^{20}$

Teologi yang dapat membawa kepada sikap mental dinamis adalah teologi yang mempunyai kebebasan berkehendak dan berbuat (free will and free act), bukan paham fatalisme (Jabariyah). Sayyid Ahmad Khan percaya bahwa manusia mempunyai kebebasan untuk mendayagunakan apa yang telah Tuhan berikan kepada manusia untuk kehidupannya yang lebih baik. Dan ia juga percaya bahwa di alam ini, Allah Swt telah mengatur ciptaan-Nya dengan hukum sunnatullah. ${ }^{21}$ Dengan kata lain, Sayyid Ahmad Khan tidak setuju umat Islam India hanya taklid dan menyeru untuk melakukan ijtihad. Bagi Sayyid Ahmad Khan paham Qadariyah dan paham Mu'tazilah perlu dikembangkan untuk membangkitkan kemajuan Islam sebagaimana yang terjadi di era Abbasiyah.

Akal merupakan potensi manusia yang paling utama dan merupakan anugerah Tuhan yang paling tinggi nilainya. Manusia menjadi bernilai adalah karena akalnya. Tanpa akal manusia tidak ada bedanya dengan hewan dan mahluk hidup lainnya. Manusia yang ingin maju perlu menggunakan akalnya. Sayyid Ahmad Khan telah memberikan penghargaan yang tinggi terhadap akal dan memercayai akan kekuatannya, namun sebagai seorang yang beragama, ia masih memercayai keterbatasan akal itu.

Sayyid Ahmad Khan dikenal sebagai pemikir rasional yang sepakat dengan paham Qadariyah dan Mu'tazilah. Hal ini dapat dilihat bahwa manusia, khususnya umat Islam India perlu memberikan ruang gerak yang besar bagi penggunaan akal

19 J. Rosenthal, Islam In the Modern National State (New York: Cambridge University Press, 1905)., h. 191.

${ }^{20}$ Fazlur Rahman, Islam Dan Modernitas Diterjemahkan Oleh Ahsin Mohammad (Bandung: Pustaka, 1985)., h. 184.

${ }^{21}$ Husain Ishtiaq Qureshi, Ulema in Politics : A Study Relating to the Political Activities of the Ulema in the South-Asia Subcontinent from 1556-1947 (Pakistas: Ma'arif Limited, 1974)., h. 226. 
dan menggunakan akal semaksimal mungkin. Ia meyakini bahwa Islam adalah ciptaan Tuhan, alam juga ciptaan Tuhan, maka Islam tidaklah mungkin bertentangan dengan ilmu pengetahuan, karena keduanya berasal dari satu, yakni Allah Swt. Oleh karena itu, umat Islam mestilah mendayagunakan akalnya untuk menciptakan ilmu pengetahuan, sehingga melahirkan teknologi-teknologi yang membuat Islam akan maju. Jika Islam tidak mengambil sikap seperti itu, maka Islam tidak akan punya masa depan. ${ }^{22}$

Inilah salah satu gagasan yang dicetuskan oleh Sayyid Ahmad Khan yakni orang-orang Islam di zaman klasik mengalami kemajuan, karena menggunakan akal pikirannya sehingga berkembanglah ilmu pengetahuan dalam Islam. Sejak abad pertengahan Islam mengalami kemunduran dan sejak itu pula penggunaan akal di kalangan umat Islam ikut mengalami kemunduran. Hal ini berlangsung hingga menjelang abad ke $19 .^{23}$

Dengan demikian, apa yang dilakukan Sayyid Ahmad Khan termasuk salah satu aspek pembaharuan dalam Islam, Ia melihat bahwa peradaban barat maju karena ilmu pengetahuan dan teknologinya. Ilmu pengetahuan dan teknologi adalah hasil pemikiran manusia. Oleh karena itu, menurutnya agar umat Islam bisa maju, akal harus mendapat penghargaan yang tinggi. ${ }^{24}$ Umat Islam, khususnya muslim India harus menggunakan akal untuk berpikir rasional, melakukan ijtihad dan meninggalkan cara berpikir konservatif yang tidak sesuai dan relevan dengan perkembangan zaman.

\section{Politik Diplomasi}

Menyadari kelemahan yang dimiliki umat Islam India, membuat Sayyid Ahmad Khan melakukan refleksi dan memikirkan solusi yang terbaik dalam penyelesaian "perseteruan" antara masyarakat India dan penjajah Inggris.

\footnotetext{
${ }^{22}$ Freeland Abbot, Islam and Pakistan (New York: Cornell University Press, 1968)., h. 126-127.

${ }^{23}$ Harun Nasution, Akal Dan Wahyu Dalam Islam (Jakarta: UI Press, 1986), h. 95.

${ }^{24}$ Nasution, Pembaharuan Dalam Islam; Sejarah Pemikiran Dan Gerakan., h. 167-169.
} 
Konfrontasi atau diplomasi terhadap Inggris merupakan sebuah pilihan yang tidak bisa ditawar. Dalam pilihan itu, Sayyid Ahmad Khan memilih diplomasi sebagai pilihan politik dalam mengembangkan dan memajukan Islam di India. Menurutnya, diplomasi bukanlah pilihan takut dan tunduk pada kerajaan Inggris, tetapi merupakan pilihan realistis dengan berkaca bahwa Inggris adalah sebuah kerajaan yang besar dan mendunia. Sebuah kerajaan yang membawa "cahaya" bidang sains dan teknologi ke India. Oleh karena itu, melakukan konfrontasi dan memusuhi kerajaan Inggris merupakan kesalahan besar, tetapi membiarkannya melakukan penindasan terhadap rakyat India/Mughal adalah suatu perbuatan yang tidak bisa dimaafkan.

Di titik inilah, Sayyid Ahmad Khan mengambil posisi berdiplomasi dengan "garis miring" melakukan kritik terhadap pemerintahan kerajaan Inggris di satu sisi, di sisi lain, menerima kebijakannya yang tidak merugikan rakyat India. Hal ini ditunjukkan pada fokusnya pembangunan infrastruktur pendidikan dan kesehatan bagi rakyat India. Dengan dua bidang ini, rakyat India dapat dan mampu lepas dari pembodohan dan kemiskinan. Fokus dalam dua hal ini merupakan ciri khas dari pemikir modernisme Islam di dunia, yang melihat bahwa pendidikan dan kesehatan menjadi hal yang urgen bagi umat Islam di mana pun berada.

Sayyid Ahmad Khan berpikir bahwa untuk memajukan sebuah negara dan wilayah dapat ditempuh bukan hanya dengan jalan perang, tetapi dapat juga ditempuh lewat pendidikan dan kesehatan sebagai jalan nir-kekerasan. Dengan berdiplomasi dengan kerajaan Inggris adalah upaya mencari jalan terbaik bagi penyelesaian konflik-konflik yang terjadi. Meski tidak pernah mengatakan dirinya sebagai seorang politikus, tetapi ketajaman visi politik yang didengkan dan diperjuangkannya menjadi landasan pacu bagi eksistensinya dalam melakuka derap langkah pembaruannya, baik di bidang pendidikan maupun dalam pemikiran keagamaan Islam di India.

Di bidang politik, Ahmad Khan berbeda dengan tokoh-tokoh Islam pada waktu itu. Ia seorang yang realistis. Bahkan ia tuduh sebagai antek kerajaan 
Inggris, yang diperbudak oleh orang kafir dari negeri seberang. Akan tetapi, Sir Sayyid Ahmad Khan kukuh dengan pendiriannya dengan menjelaskan secara rasional terhadap orang yang mengeritiknya. Ia beranggapan bahwa Inggris adalah penguasa yang terlalu kuat di India waktu itu. Kekuatannya ditopang oleh kemajuannya di bidang ilmu dan teknologi yang tidak dimiliki oleh rakyat India, baik Muslim maupun Hindu. Melawan kekuatan yang tangguh itu ibarat melawan gajah dengan semut, sangat susah dikalahkan, apalagi kondisi umat Islam yang terkotak-kotak dan tidak bersatu padu. Dengan demikian, gerakan yang dilakukannya -dalam bahasa penulis- "menunduk tapi menanduk". Melakukan diplomasi, tetapi ketika kebijakan yang dikeluarkan oleh kerajaan Inggris hanya mengeksplotasi rakyat India, maka Sayyid Ahmad Khan adalah orang pertama yang akan berhadapan dan mengeritik kerajaan Inggris. Dengan demikian, peningkatan kualitas umat Islam India dapat diwujudkan, jika bekerja sama dengan Inggris. Ini dapat pula dimanfaatkan untuk mengambil kesempatan meraih kemajuan-kemajuan yang dimilikinya, terutama di bidang ilmu dan teknologi.

Tentu saja, ide ini menimbulkan reaksi pro dan kontra, terutama dari kalangan yang melakukan konfrontasi terang-terangan untuk mengusir kekuatan Inggris di India. Namun, mereka yang sadar atas kondisi dan kenyataan yang ada, dapat juga menerimanya. Dalam merealisasikan idenya, Ahmad Khan berusaha membujuk kedua belah pihak agar mau melepaskan sikapnya selama ini. Umat Islam tidak boleh lagi anti-Inggris dan Inggris harus melenyapkan prasangka buruknya terhadap umat Islam. Pada tahun 1858, dalam mengejawantahkan gagasannya, ia pun menulis dua buku yang diberi judul "Tarikh Sarkhasi Bijnaur"25 dan "Asbab al-Bagawah al-Hind"26 yang isinya memuat penilaian

${ }^{25}$ Tarikh Sarkhasi Bijnaur (1858), berisi catatan secara kronologis peristiwa 1857 yang terjadi di Bijnaur, ketika ia bertugas sebagai pegawai Inggris pada waktu itu. Lihat Dewan Redaksi Ensiklopedi Islam., h. 86.

${ }^{26}$ Dalam bukunya Asbab al-Bagawah al-Hind, Ahmad Khan berusaha meyakinkan pihak Inggris bahwa dalam pemberontakan 1857, umat Islam tidak memainkan peranan utama. Untuk itu, dalam buku ini, ia menjelaskan sebab-sebab yang membawa pecahnya pemberontakan 1857, di antaranya: (1) intervensi Inggris dalam soal keagamaan, seperti pendidikan agama Kristen yang diberikan kepada anak yatim piatu di panti-panti yang diasuh oleh orang Inggris, pembentukan sekolah-sekolah misi Kristen dan penghapusan pendidikan agama di perguruan-perguruan tinggi, 
obyektif terhadap peristiwa 1857 sebagai puncak ketegangan hubungan umat Islam dan pemerintah Inggris di India. Ia menulis bahwa pihak Inggris tidak melihat secara jeli bahwa dalam kelompok Islam, ada kelompok konfrontasi dan diplomasi terhadap Inggris. Dalam peristiwa 1857, memang benar bahwa kelompok Islam terlibat, tetapi "memukul-rata" dengan mengatakan bahwa semua kelompok Islam terlibat merupakan hal yang keliru dan salah kaprah. Oleh karena itu, merupakan kesalahan besar, jika pihak kerajaan Inngris menaruh curiga dan anti-pati kepada seluruh umat Islam. Dan menjadikan umat Islam sebagai biang keladi dan aktor utama dalam peristiwa tersebut.

Salah satu kunci utama Ahmad Khan dalam meyakinkan Inggris adalah konsistensi akan loyalitasnya. Loyalitas utama yang pernah ditunjukkan adalah ketika Ahmad Khan memberi perlindungan terhadap orang Eropa yang sedang berada dalam ancaman kaum nasionalis India pada masa berlangsungnya perang Mutiny. ${ }^{27}$ Sejak itu, ia dianggap berjasa oleh pihak penguasa Inggris, sehingga dapat memulihkan kepercayaan mereka terhadap umat Islam.

Upaya lain yang dilakukan oleh Ahmad Khan dalam memulihkan kepercayaan penguasa Inggris terhadap masyarakat Islam ialah menulis beberapa buku yang membahas tentang loyalitas umat Islam terhadap pemerintah Inggris. Buku-buku tersebut di antaranya adalah The Loyal Muhammadans of India (1860). Buku ini memuat nama-nama orang Islam terkemuka yang memihak kepada Inggris, pada saat terjadinya pemberontakan Mutiny. Buku lainnya berjudul The Causes of Indian Revolt, menerangkan tentang kekuasaan pemerintah Inggris dalam menjalankan roda pemerintahannya, sehingga pecah pemberontakan

(2) tidak turut sertanya orang-orang India, baik Islam maupun Hindu dalam lembaga-lembaga perwakilan rakyat, yang tentunya hal ini membawa kepada: (a) rakyat India tidak mengetahui tujuan dan niat Inggris, bahkan mereka menganggap bahwa Inggris datang untuk mengubah agama mereka menjadi Kristen, (b) pemerintah Inggris tidak mengetahui keluhan-keluhan rakyat India, (3) pemerintah Inggris tidak berusaha mengikat tali persahabatan dengan rakyat India. Sedangkan kestabilan dalam pemerintahan bergantung pada hubungan baik dengan rakyat. Sikap tidak menghargai dan tidak menghormati rakyat India, membawa pada akibat yang tidak baik. Lihat Nasution, Pembaharuan Dalam Islam; Sejarah Pemikiran Dan Gerakan., loc. cit.

27 Ali., h. 59. 
Mutiny. Pada mulanya, buku ini dinilai oleh pihak Inggris sebagai tulisan yang menghasut mereka. Namun, karena mayoritas di kalangan pihak Inggris telah mengakui dan mempercayai loyalitas Ahmad Khan, maka tidak ada sanksi apa pun yang ditimpakan kepadanya.

Proses tidak pernah mengkhianati hasil merupakan ibarat yang pantas dilekatkan pada usaha keras Sayyid Ahmad Khan dalam memahamkan kerajaan Inggris atas ketidak-terlibatan umat Islam dalam pemberontakan 1857. Selain itu, ia juga menunjukkan sikap lemah lembut dan persekawanan yang baik terhadap Inggris, maka Ahmad Khan akhirnya berhasil mengubah pandangan Inggris terhadap umat Islam India. Dan di sisi lain, Sayyid Ahmad Khan meganjurkan kepada umat Islam India agar tidak melakukan pertentangan keras terhadap Inggris dan menunjukkan sikap kritis jika merugikan umat Islam India. Serta menjalin hubungan yang baik dengan pihak Inggris sambil menyerap pengetahuan yang dibawa dari negaranya. Sayyid Ahmad Khan sangat mengharapkan dan mencitacitakan terjalinnya hubungan baik antara Inggris dan umat Islam, agar umat Islam dapat ditolong darin kemundurannya dan dapat mewujudkan masa depannya. ${ }^{28}$

\section{Paham Naturalistik (Hukum Alam).}

Berkenaan dengan paham Qadariyah yang dianutnya, ia berkeyakinan bahwa akal manusia mempunyai kemampuan yang kuat dalam meraih kesejahteraan hidup. Dalam pandangan Islam, Tuhan menciptakan manusia yang memiliki perbedaan, sehingga berbeda pendapat merupakan sesuatu yang manusiawi dan absah. ${ }^{29}$ Ia juga berpendirian bahwa manusia bebas berkehendak dan berbuat sesuai dengan hukum alam atau Sunnatullah yang tidak berubah. Jadi, perpaduan antara kemampuan akal, kebebasan manusia berkehendak dan berbuat, serta hukum alam inilah yang menjadi sumber kemajuan ilmu pengetahuan dan teknologi modern yang terdapat di Barat.

\footnotetext{
${ }^{28}$ Nasution, Pembaharuan Dalam Islam; Sejarah Pemikiran Dan Gerakan., h. 167.

${ }^{29}$ Muhammad Nur Murdan, 'Membangun Hubungan Antara Ummat Dan Kekuasaan: Konsep Negara Dalam Piagam Madinah’, Pappasang, 1.1 (2019)., h. 63-64.
} 
Sayyid Ahmad Khan meyakini bahwa segala sesuatu yang terdapat di alam ini, terjadi menurut hukum kausalitas (sebab-akibat), dan sebab pertama itu adalah Tuhan. ${ }^{30}$ Lebih jauh, ia meyakini bahwa setiap makhluk ciptaan Tuhan telah menentukan tabiatnya (nature), jadi proses sebab-akibat yang terjadi merupakan suatu ketetapan Tuhan dan akan berlangsung secara mekanik tanpa berhubungan langsung lagi dengan Tuhan sebagai penyebab pertama. Jadi, pemunculan sebuah realitas dari hukum-hukum alam merupakan wujud dasar dari pemikiran manusia yang bersumber dari akal.

Dalam bahasa Agama, nature dinamakan sunnatullah yang tidak berubah. Sebagaimana dikalangan ilmuan Barat menamakannya sebagai hukum alam (Natural Law). Adapun korelasinya antara hukum alam dan Al-Quran tidaklah terdapat pertentangan, oleh karena itu, Islam adalah agama yang mempunyai paham hukum alam (hukum alam buatan Tuhan). Jadi, keduanya mesti sejalan, baik Al-Qur'an sebagai sabda Tuhan maupun hukum alam (Sunnatullah) sebagai ciptaan Tuhan.

Menurut Ahmad Khan Al-Quran sebagai firman Tuhan harus sesuai dengan hukum alam yang dianggapnya sebagai perbuatan Tuhan. Hukum alam sebagaimana pemaknaan para Scientist Barat telah berhasil mengungkapkan bahwa segala sesuatu di alam ini mematuhi suatu aturan atau hukum yang bersifat mekanis dan tak berubah. Jadi, segala sesuatu terjadi menurut hukum sebab-akibat. Lebih dikuatkan lagi oleh Ahmad Khan dengan beranggapan bahwa paham naturenya berTuhan. Tuhan yang menjadi penyebab dari segala sebab terjadinya sesuatu atau disebut juga sebab pertama. Dan segala sesuatu terjadi karena hukum sebab-akibat yang terus berlaku itu. Hukum alam menurut pendapatnya adalah tabiat yang diciptakan bagi setiap makhluknya yang tetap berlaku dan tidak berubah $^{31}$.

\footnotetext{
${ }^{30}$ Dewan Redaksi Ensiklopedi Islam., h. 86.

${ }^{31}$ Dewan Redaksi Ensiklopedi Islam., h. 87.
} 
Selain itu, dengan berlandaskan pada hukum alam (Sunnatullah), Ahmad Khan melakukan reinterpretasi terhadap konsep-konsep dalam Al-Qur'an seperti Mu'jizat, Malaikat, Syaitan dan Jin. ${ }^{32}$ Dan tidak terlupakan juga mengenai persoalan-persoalan hukum (fiqh), seperti perkawinan dalam Islam, hukum potong tangan dan perbudakan. ${ }^{33}$ Hasil interpretasinya relatif jauh berbeda dari apa-apa yang telah ditetapkan oleh ulama-ulama masa lalu. Oleh karena itu, menurut pendapatnya sumber ajaran Islam hanya Al-Qur'an dan Hadis. Adapun pendapat ulama di masa lampau tidaklah harus diikuti, bahkan jika tidak sesuai lagi dengan perkembangan zaman modern, maka pendapat tersebut harus ditinggalkan. ${ }^{34}$

Sementara itu dalam menginterpretasikan pesan-pesan Al-Qur'an yang tampak sulit dipahami dalam keadaan konteks modern. Ia interpretasikan secara Simbolis, Alegoris dan Analitis untuk makna sebenarnya, sehingga selalu konsisten dengan akal dan tidak pernah berubah apalagi bertentangan dengan hukum alam. ${ }^{35}$

\section{E. Simpulan}

Adapun kesimpulan yang dapat ditarik dalam uraian di atas, sebagai berikut:

${ }^{32}$ Adapun mengenai Mu'jizat ia mengatakan: bahwa mu'jizat adalah suatu peristiwa yang tidak mengalami hukum alam. Kekaguman manusia terhadap mu'jizat karena peristiwa itu menyalahi hukum kebiasaan. Sedangkan Malaikat bukanlah makhluk yang bersayap dan dapat berubah bentuk. Tetapi ia hanyalah kekuatan alam, sebagaimana syaitan, keduanya adalah sesuatu yang ada dalam diri manusia: Malaikat adalah kekuatan untuk kebaikan dan Syaitan adalah kekuatan untuk berbuat jelek dan jahat. Adapun Jin adalah bangsa primitif yang hidup disemenanjung Arab dan tunduk pada Nabi sulaiman. Lihat Muktaf Sahal, Teologi Islam Modern (Surabaya: Gitamedia Press, 1999)., h.78.

${ }^{33}$ Nasution, Pembaharuan Dalam Islam; Sejarah Pemikiran Dan Gerakan.

${ }^{34}$ Nasution, Pembaharuan Dalam Islam; Sejarah Pemikiran Dan Gerakan., h. 168.

${ }^{35}$ Ira M. Lapidus, History of Islamic Societies (London: Cambridge University Press, 1988)., h. 728. 
1. Akibat penjajahan yang dilakukan oleh kerajaan Inggris di India, membuat masyarakat India terjajah dan tereksploitasi secara terus-menerus, yang mengakibatkan umat Islam India mempunyai rasa kalah dan pasrah yang berkepanjangan dan mempunyai jiwa "mental inlader". Melihat akan hal itu, Sir Sayyid Ahmad Khan menyerukan kepada umat Islam untuk menginternalisasi paham Qadariyah, sebuah paham dalam teologi Islam yang berpendapat bahwa manusia mempunyai kemerdekaan dan kebebasan dalam menentukan perjalanan hidupnya.

2. Sir Sayyid Ahmad Khan dalam memperjuangkan India dan Islam dari penjajahan Inggris mengambil metode diplomasi, bukan konfrontasi. Bagi Sayyid Ahmad Khan dengan menggunakan metode diplomasi adalah metode yang menguntungkan bagi masyarakat India dan Islam, sebab Inggris datang ke India membawa "pencerahan" pengetahuan teknologi modern. Darinya rakyat India dapat belajar untuk kemudian memerdekan India dan memajukan umat Islam India. Sir Sayyid Ahmad Khan menolak metode konfrontasi dengan penjajah Inggris, karena konfrontasi hanya akan mrugikan umat Islam India.

3. Sayyid Ahmad Khan meyakini bahwa segala sesuatu yang terdapat di alam ini, terjadi menurut hukum kausalitas (sebab-akibat), dan sebab pertama itu adalah Tuhan.36 Lebih jauh, ia meyakini bahwa setiap makhluk ciptaan Tuhan telah menentukan tabiatnya (nature), jadi proses sebab-akibat yang terjadi merupakan suatu ketetapan Tuhan dan akan berlangsung secara mekanik tanpa berhubungan langsung lagi dengan Tuhan sebagai penyebab pertama.

\footnotetext{
${ }^{36}$ Dewan Redaksi Ensiklopedi Islam., h. 86.
} 


\section{F. DAFTAR PUSTAKA}

Abbot, Freeland, Islam and Pakistan (New York: Cornell University Press, 1968)

Ali, Mukti, Alam Pikiran Islam Modern Di India Dan Di Pakistan, IV (Bandung: Mizan, 1998)

Amin, Saidul, 'Pembaharuan Pemikiran Islam Di India', Jurnal Ushuluddin, XVIII.1 (2012)

Amir, Ahmad Nabil Bin, 'Sir Sayyid Ahmad Khan Dan Gerakan Pembaharuan Aligarh Di India', El-Buhuth, 2.2 (2020)

Arifin, Zainur, 'Politik Pendidikan Islam Masa Modern: Membaca Gagasan Tokoh Pembaharu Di Negara Turki, India Dan Mesir', Tafaqquh: Jurnal Penelitian Dan Kajian Keislaman, 3.1 (2015)

Dewan Redaksi Ensiklopedi Islam, 'Ensiklopedi Islam' (Ichtiar Baru Van Hoeve, 1993)

Dulumina, Gunawan B., 'Gerakan Pembaruan Sayyid Ahmad Khan', Hunafa, 2.2 (2005)

Faruki, Kemal A., 'Pakistan: "Islamic Government and Society", in Islam Ind Asia, Religion, Politics, and Society (Oxford: Oxford University Press (OUP), 1987)

Gibb, H.A.R. dan J.H. Krames, Shorter Encyclopedia of Islam (Leiden: E. J. Brill, 1961)

Houtsma, Martijn Theodoor, The First Encyclopedia of Islam (Leiden: E. J. Brill, 1987)

Lapidus, Ira M., History of Islamic Societies (London: Cambridge University Press, 1988)

Murdan, Muhammad Nur, 'Membangun Hubungan Antara Ummat Dan

Kekuasaan: Konsep Negara Dalam Piagam Madinah', Pappasang, 1.1 (2019)

Nasution, Harun, Akal Dan Wahyu Dalam Islam (Jakarta: UI Press, 1986)

Pembaharuan Dalam Islam; Sejarah Pemikiran Dan Gerakan, IX (Jakarta: Bulan Bintang, 1992)

_- Teologi Islam: Aliran-Aliran Sejarah Analisa Perbandingan (Jakarta: UI Press, 1986)

Qureshi, Husain Ishtiaq, Ulema in Politics: A Study Relating to the Political Activities of the Ulema in the South-Asia Subcontinent from 1556-1947 (Pakistas: Ma'arif Limited, 1974)

Rahman, Fazlur, Islam Dan Modernitas Diterjemahkan Oleh Ahsin Mohammad (Bandung: Pustaka, 1985)

Rizqa, Hasanul, 'Pemikiran Sayyid Ahmad Khan Tentang Pendidikan', Republika.Co.Id(Jakarta, 8 April 2019) 
Rosenthal, J., Islam In the Modern National State (New York: Cambridge University Press, 1905)

Sahal, Muktaf, Teologi Islam Modern (Surabaya: Gitamedia Press, 1999)

Smith, W.C., Modern Islam In India: A Social Analiysis (London: Oxford University Press, 1946) 